\title{
ESTRATÉGIA EM NEGÓCIOS INTERNACIONAIS: EVIDÊNCIA EM UMA \\ TRADING COMPANY QUE ATUA ENTRE ECONOMIAS EMERGENTES
}

\author{
Karim Marini Thomé \\ thome@unb.br \\ Universidade de Brasília - Brasília, DF/Brasil \\ Janann Joslin Medeiros \\ janann@unb.br \\ Universidade de Brasília - Brasília, DF/Brasil \\ Cristina Lélis Leal Calegário \\ ccalegario@dae.ufla.br \\ Universidade Federal de Lavras - Lavras, MG/Brasil
}

Recebido em 05/12/2011

Aprovado em 07/11/2012

Disponibilizado em 01/04/2013

Avaliado pelo sistema double blind review

Revista Eletrônica de Administração

Editor: Luís Felipe Nascimento

ISSN 1413-2311 (versão on-line)

Editada pela Escola de Administração da Universidade Federal do Rio Grande do Sul.

Periodicidade: Quadrimestral

Sistema requerido: Adobe Acrobat Reader.

\section{RESUMO}

No presente estudo retomam-se os questionamentos de Peng $(2004 ; 2003)$ a respeito do que direciona a estratégia da firma e do que determina o sucesso ou o fracasso em negócios internacionais. Mais especificamente, investiga-se o que direcionou a estratégia de uma trading company e o que determinou o seu sucesso em negócios internacionais. O referencial teórico é dividido em duas partes. A primeira diz respeito ao negócio da trading company, pautada na atuação triangular de relacionamento entre trading company, clientes e fornecedores. Na segunda parte versa-se sobre as distintas abordagens ou bases da estratégia em negócios internacionais: competição industrial, recursos e capacidades da firma e condições e transições institucionais. O estudo é de natureza descritiva e qualitativa. Na coleta dos dados primários foram utilizados roteiro de entrevistas em profundidade, observação direta não participativa e análise documental, ao longo dos meses de julho de 2010 a janeiro de 2011. O caso selecionado para estudo é uma trading company que apresenta elevado volume transacionado entre economias emergentes. Os resultados evidenciaram que não há direcionador único na estratégia da trading company estudada. O que se observou foi uma variedade de estratégias baseadas ora em competitividade industrial, ora em recursos e capacidades da firma, ora em condições institucionais. Cada direcionador correspondeu, assim, a um determinado momento na trajetória da trading company estudada. Da mesma maneira, não foi observada uma ordem cronológica linear entre os direcionadores, tampouco a obsolescência dos direcionadores. Ao contrario, as evidências apontam que os direcionadores

REAd I Porto Alegre - Edição 74 - N 1 - jan/abr 2013 - p. 219-246 
Estratégia em negócios internacionais: evidência em uma trading company que atua entre economias emergentes

são cumulativos e cíclicos, e necessitam ser revisados e, até mesmo, repensados, em função de atributos organizacionais e de contexto ambiental que se modificam. O determinante de sucesso da trading company estudada em negócios internacionais entre economias emergentes foi identificado como a capacidade da firma em gerenciar as interfaces entre os recursos e capacidades da firma, as demandas de competitividade industrial e as condições e transições institucionais. Esta capacidade possibilitou à firma estudada se sobressair à dificuldade e a explorar oportunidades de negócios em diferentes partes do globo.

Palavras-chave: Estratégia; Negócios Internacionais; Economias Emergentes; Trading Company

\title{
INTERNATIONAL BUSINESS STRATEGY: EVIDENCE FROM A TRADING COMPANY THAT OPERATES IN EMERGING ECONOMIES
}

\begin{abstract}
This case study revisits the questions raised by Peng (2004; 2003) with respect to what drives firm strategy and the determinants of success or failure in international business. Specifically, the study investigates what drives the strategy of a trading company and determines its success in international business. The theoretical framework focuses on trading companies and the triangular relationships between these companies, their clients and their suppliers and on three approaches or bases of strategy in international business, those of industrial competitiveness, firm resources and capabilities, and institutional contexts and transitions. The study, descriptive and qualitative in nature, collected data by means of in-depth interviews, document analysis and non-participant observation during the period from July, 2010 to January, 2011. The firm selected for study is a trading company conducting a large percentage of its total transactions between emerging economies. Results demonstrate that there is no single driver of this trading company strategy. Rather, there was evidence of the use of a variety of strategies, driven at times by the demands of industrial competitiveness, at times by firm resources and capabilities, and at times by institutional conditions. Each driver corresponded to a specific moment in the trajectory of the trading company studied. In addition, there was no evidence neither of a linear chronological order for these drivers, nor of driver obsolescence. On the contrary, the evidence of the study suggests that drivers are cumulative and cyclical, requiring review and even re-thinking when organizational and environmental characteristics undergo change. The determinant of success for the trading company studied was identified as the firm capability to manage the interfaces among firm resources and capabilities, the demands of industrial competitiveness, and institutional conditions and transitions. It is the capability to manage these interfaces that has permitted the firm to overcome the adversities and exploit the business opportunities in emerging economies around the world.
\end{abstract}

Keywords: Strategy; International Business; Emerging Economies; Trading Company.

REAd I Porto Alegre - Edição 74 - Nº 1 - jan/abr 2013 - p. 219-246 
Karim Marini Thomé, Janann Joslin Medeiros \& Cristina Lélis Leal Calegário

\section{INTRODUÇÃO}

Trading companies são frequentemente estudadas em sistemas de distribuição, mais especificamente na literatura de canais ou de cadeias (COUGHAN et al., 2002). Na maioria das vezes, as trading companies são retratadas como nas palavras de Chintakananda, York, O`Neil e Peng (2009, p. 304): “empresas de serviços especializadas em dar suporte na conexão de produtores de um país com seus compradores internacionais", dando assim a impressão que são intermediadoras comerciais que estabelecem relações lineares com fornecedores e também com compradores para efetuar ganhos sobre as transações decorrentes entre estes.

Temas acadêmicos que visualizam parte/fração da atuação das trading companies, tais como fatores influentes na seleção e comprometimento entre trading companies e indústrias, desempenho de firmas que utilizam trading companies para exportar, papel de facilitador de comércio de trading companies e relacionamentos bilaterais/dependência envolvendo trading companies (MADSEN: MOEN; HAMMERVOLD, 2012; AHN; KHANDELWAL; WEI, 2011; ANTRÀS; COSTINOT, 2011, CHINTAKANANDA et al., 2009; PENG et al., 2006; LAGES; MONTGOMERY, 2004) são recorrentes. Contudo, estudos que analisem a atuação de trading companies de maneira holística - ou seja, como parte de uma relação tripartite entre fornecedores e compradores nos negócios internacionais contemporâneos - são escassos. Quando se trata de um olhar estratégico a respeito de sua atuação, mais que escassos, são raros.

$\mathrm{O}$ atual ambiente de negócios vivido pelas trading companies é muito mais complexo que a turbulência descrita por Achrol (1991) e é devido ao aumento vertiginosa da globalização. Na visão de Ellis (2001), a globalização ameaça significativamente as trading companies. Segundo ele, o desenvolvimento de tecnologias para comunicação, transporte e sistemas bancários/financeiros, combinado com a crescente internacionalização de indústrias e agentes varejistas, tem remodelado diversas atribuições das chamadas tradicionais funções de distribuição internacional, entre elas as desempenhadas por trading companies.

Observa-se, ainda, que os estudos de negócios internacionais tendem a focá-los no sentido mercado desenvolvido/emergente ou inverso (KEDIA; GAFFNEY; CLAMPIT, 2012 WRIGHT et al., 2005), o que não oferece um quadro completo do comercio internacional contemporâneo.

REAd I Porto Alegre - Edição 74 - № 1 - jan/abr 2013 - p. 219-246 
Estratégia em negócios internacionais: evidência em uma trading company que atua entre economias emergentes

Neste contexto, o presente estudo visa contribuir para a melhor e mais completa compreensão do atual papel e atuação das trading companies, à luz dos questionamentos de Peng $(2004 ; 2003)$ a respeito do que direciona a estratégia da firma e do que determina o sucesso ou o fracasso em negócios internacionais. Procura-se compreender a atuação de uma trading company no sentido amplo do conceito, de maneira holística, incorporando as ideias de Peng, Wang e Jiang (2008) e Peng e Pleggenkuhle-Miles (2009) a respeito da estratégia em negócios internacionais e focalizando um caso que envolve transações entre economias emergentes.

Mais especificamente, o estudo se propõe a investigar o que direciona a estratégia de uma trading company e o que determinou o sucesso da mesma em negócios internacionais. Para elucidar estes questionamentos o artigo conta o referencial teórico na seção dois, procedimentos metodológicos na terceira seção, seguidas pela análise e discussão dos dados e por fim as considerações finais contendo as limitações e sugestões para estudos futuros.

\section{REFERENCIAL TEÓRICO}

Adota-se, neste estudo, um conceito de trading companies mais amplo que aquele de Chintakananda et al. (2009), que os caracterizam como agentes de suporte ou facilitadoras de transações. Considera-se que a atuação dessas empresas é complexa e se caracteriza por especialização em intermediação com base em comissões ou revendas de produtos (ELLIS, 2001; PENG; YORK, 2001). Esta intermediação envolve múltiplos agentes que se interrelacionam em direções horizontais e/ou verticais, assim como a participação ativa na estruturação das transações (FUNG et al., 2007; HAVILA et al., 2004; DYER; SINGH, 1998; HAKANSSON; SNEHOTA, 1995).

\subsection{O negócio da trading company}

A trading company, como comentado anteriormente, encontra-se situada na interlocução de agentes, se posicionando como elo fundamental numa relação triangular entre fornecedor e cliente na conduta de seu negócio. A relação triangular, ou de tríade, vem do termo triad ou triadic. Apesar de não ter uma tradução consagrada no português, o termo, 
Karim Marini Thomé, Janann Joslin Medeiros \& Cristina Lélis Leal Calegário

como utilizado na análise de relações comerciais, significa uma relação tripartite (GRANOVETTER, 1973).

De acordo com Havila et al. (2004), a triad pode ser aplicada em relações com intermediários de duas maneiras. Utilizando-se a Figura 1 para explicar as duas situações no contexto do negócio da trading company, tem-se:

i) interação fechada, em que exista influência de igual, ou muito próxima a igual, intensidade entre os três atores participantes do relacionamento, ou seja, as ligações A, B e C apresentam o mesmo vigor e acontecem simultaneamente. Neste caso, a trading company atua como comissionado, tendo a função de assessorar ou agir como interlocutor de um específico fornecedor ou cliente e

ii) interação aberta, com diferentes intensidades de interações entre os agentes, havendo interações da trading company com cliente (B) e também com fornecedor (A) para que, consequentemente, seja realizada a transação do fornecedor para o cliente (C), desse modo caracterizando um sistema aberto no qual as relações A e B precedem a relação C.

Percebe-se que, na interação aberta, a trading company atua como revendedor/atravessador, detendo o direito de propriedade do produto e impactando diretamente a formação do preço do produto transacionado. Nesse caso, realmente as relações são bilaterais, A e B, quando a trading company percebe possibilidades de ligações $\mathrm{C}$ entre demandantes e fornecedores, que lhe sejam benéficas. Já na interação fechada, a trading atua como uma espécie de corretora, que apresenta uma relação com fornecedor e comprador, e intermedia a relação em que o fornecedor vende ao comprador. Ou seja, na interação aberta, a trading company efetua compra e venda bilateralmente, enquanto na outra situação não compra ou vende nada, participa ao longo do processo e recebe uma porcentagem da venda de uma ou outra parte (ou as duas).

REAd I Porto Alegre - Edição 74 - № 1 - jan/abr 2013 - p. 219-246 
Estratégia em negócios internacionais: evidência em uma trading company que atua entre economias emergentes

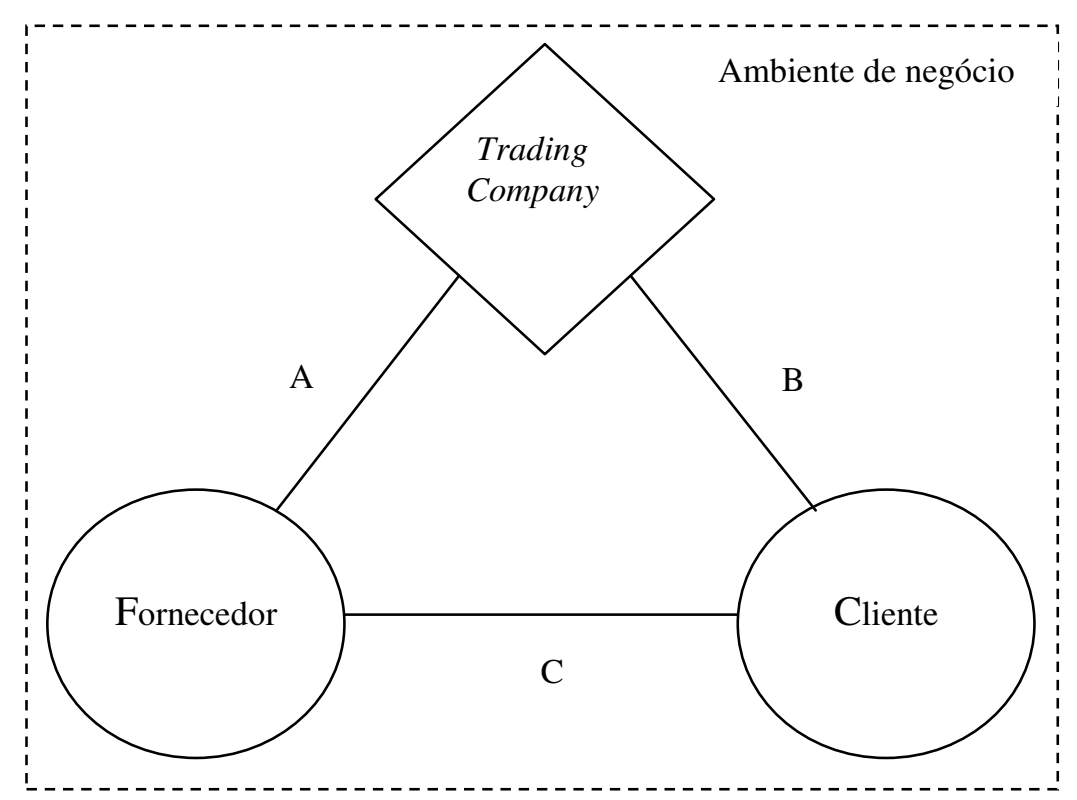

Figura 1 - Estrutura de triad

Fonte: Adaptado de Fung et al. (2007) e Havila et al. (2004).

A triad, assim como qualquer outra rede de negócios, é entendida como um sistema orgânico que pode ser estudado, dependendo da natureza de seu questionamento, com base em relacionamentos, estruturas, posições e processos (EASTON, 1992). Percebe-se, pela leitura de Easton (1992), que relações dyadics podem ser utilizadas para analisar redes interorganizacionais, contudo, dada a natureza do negócio da trading company, a unidade de análise de triad traz aporte meso-analítico e permite aprofundar a compreensão holística das relações envolvidas.

Na Figura 1 retrata-se a relação de triad que é resultado das interconexões da trading company com um fornecedor e um cliente. Contudo, não expressa a total gama de possibilidades de interações do seu portfólio, já que trading companies não têm interação apenas com um fornecedor e/ou um cliente, mas, sim, com um portfólio de possíveis fornecedores e clientes (ELLIS, 2001).

As interações representadas pelas linhas A, B e C, na Figura 1, além das dificuldades decorrentes das negociações e transações expressas em Williamson (1991), acontecem em comércio internacional e se caracterizam por serem realizadas em contextos caracterizados por condições institucionais complexas, decorrentes de diferenças culturais, políticas, geográficas, normativas e legais dos países de origem de fornecedores e clientes. Lidar com essa complexidade e contornar as dificuldades decorrentes das diferentes condições 
Karim Marini Thomé, Janann Joslin Medeiros \& Cristina Lélis Leal Calegário

institucionais faz parte do serviço realizado pela trading company. A capacidade de lidar com adversidades deste tipo se desenvolve ao longo da trajetória da firma e passa a fazer parte do seu core business, dando possibilidade para a trading company explorar oportunidades de negócios nos mais diversos países ou regiões (JONES, 1998). O desenvolvimento de negócios estaria ligado, assim, a fatores menos deterministas e mais evolucionistas (HAKANSSON; SNEHOTA, 1995).

Sendo assim, as trading companies acabam por ver o ambiente de negócios como uma grande rede de possíveis interações não restrita necessariamente ao plano econômico, mas podendo envolver relações e atividades em outros planos (como o social e o institucional) que podem refletir no campo organizacional (PENG et al., 2008; RAUCH, 2001; HAKANSSON; SNEHOTA, 1995).

\subsection{Estratégia em negócios internacionais}

Os últimos trinta anos foram marcados por mudanças na conjuntura da economia internacional e do ambiente dos negócios. Dentre as principais mudanças destacam-se o surgimento de novos países industrializados, como Singapura e Coreia do Sul e, mais recentemente, os emergentes Brasil, Rússia, Índia e China. O impacto criado por estes países ao embarcar em transações comerciais internacionais e na expansão dessas foi tamanho que pesquisadores da área dos negócios internacionais chamam este fenômeno de terceira onda (third wave) (MARTELL, 2007; BIGGESMANN; FAM, 2011).

Foi com o olhar sobre este contexto que Peng (2004; 2003) questionou os fatores estratégicos que direcionam a firma e os possíveis focos determinantes de sucesso e fracasso organizacional na área de negócios internacionais. Tais indagações acabaram por resultar em um complemento às teorias estratégicas baseadas na competição industrial (PORTER, 1985) e nos recursos (BARNEY, 1991) que retomam a discussão das instituições levantadas por North (1990) e Scott (1995), colocando, assim, a visão baseada nas instituições como uma nova temática neste campo de pesquisa, formando, dessa forma, o que Peng et al. (2008) e Peng (2006) chamam de tripé de sustentação estratégica, expressa na Figura 2.

Apesar de Peng et al. (2008) reconhecerem a importância da competição industrial e dos recursos e capacidades da firma, eles ressaltam que as instituições formais e informais 
Estratégia em negócios internacionais: evidência em uma trading company que atua entre economias emergentes

acabam sendo negligenciadas e isso veio à tona quando países emergentes ou em desenvolvimento tornaram-se destaque na esfera econômica.

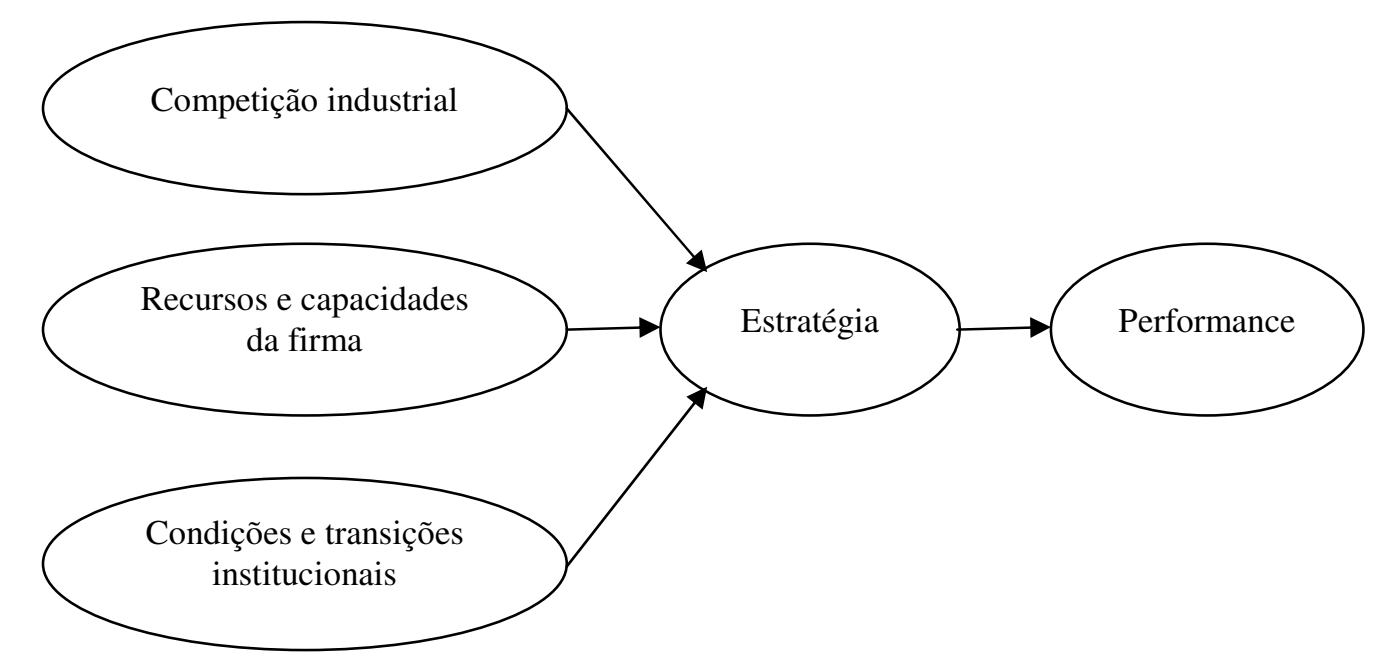

Figura 2 - As três pernas de sustentação estratégica.

Fonte: Peng et al. (2008, p.923).

O institucionalismo discutido por Peng et al. (2008) e Peng e Pleggenkuhle-Miles (2009) é, sobretudo, norteado em North (1990), que conceitua instituições como as "regras do jogo" que normatizam a interação entre firmas e em Scott (1995), que as conceitua como estruturas regulatórias, normativas e cognitivas que provêm estabilidade ao comportamento social. Tomadas em conjunto, as duas perspectivas institucionalistas propiciam óticas formais e informais sobre seu objeto.

Foi sob esta perspectiva institucional que Peng (2003, p. 275) apontou como uma das características dos mercados emergentes a "propensão de mudanças conjunturais nas regras formais e informais do jogo que afetam as firmas como jogadores", rotuladas por ele como “instituições transitórias”. Este fato é também ressaltado por Meyer e Peng (2005) e é tratado, nos casos estudados por estes autores, como consequência da transformação do sistema geopolítico e econômica. Focando na transição socialista para capitalista em países do centro e leste europeu, sobretudo na Rússia, estes autores observaram as dificuldades/barreiras para a atuação de empresas estrangeiras nesse mercado postas por essas regras do jogo, como evidenciados nos trabalhos de Aidis e Adachi (2007).

Outros exemplos de significativa repercussão de atributos institucionais são encontradas em Estrin e Prevezer (2010) e em Faruq (2011). No primeiro trabalho, Estrin e 
Karim Marini Thomé, Janann Joslin Medeiros \& Cristina Lélis Leal Calegário

Prevezer (2010) evidenciam diferentes problemas de entrada e saída de firmas em detrimento de diferentes constituições institucionais nos países hospedeiros do BRIC e em Faruq (2011) foi identificado que existe relação entre atributos institucionais (corrupção, burocracia e seguridade nos direitos de propriedade) e qualidade das exportações.

Peng et al. (2008) argumentam que as condições e transições institucionais constituem um fator que influencia a estratégia da firma em ambiente de negócios internacionais em pé de igualdade com a estrutura industrial e os recursos e capacidades da firma, posição mantida no estudo de Peng e Pleggenkuhle-Miles (2009), que trata a abordagem institucional como elo que liga vários debates atuais no campo de estratégia global.

Assim, com a finalidade de identificar o direcionador da estratégia de uma trading company, bem como seu fator determinante para o sucesso em negócios internacionais, adotase o tripé de sustentação estratégica proposto por Peng et al. (2008), ou seja, competição industrial, recursos e capacidades e condições e transições institucionais.

Como atributos da competição industrial capazes de propiciar liderança em custos, segmentação e/ou diferenciação (PORTER, 1985), se utilizam aqui as mesmas variáveis que Ellis (2001) utilizou - especialização e diversificação, ao longo de três dimensões: produto (natureza), geografia (locais de fornecedores e clientes) e função (atravessador e/ou comissionado).

Com respeito aos recursos e capacidades, a teoria baseada nos recursos, assim como a teoria da rede de negócios, evidencia que fatores idiossincráticos relacionados à trajetória podem moldar a firma e/ou a rede (BARNEY et al, 2001; DYER; SINGH, 1998; BARNEY, 1991). Na teoria da visão baseada em recursos, firmas procuram acumular recursos que variam em raridade, possibilidade de imitação, escassez, possibilidade de comercialização (BARNEY et al., 2001). Peng (2001) confirma a possibilidade da aplicação desta teoria em ambiente international e afirma que recursos acumulados em negócios internacionais podem gerar vantagens para os seus detentores. Ele chama a atenção para o capital social desenvolvido em redes de negócios e para o conhecimento tácito que a empresa desenvolve e procura manter em operações globais, tratando-os como recursos distintivos (MILLS et al., 2002).

Estabelecer ponte entre a visão baseado em recursos e a visão baseada em instituições é a ideia de Wright et al. (2005), que permite compreender que, em economias emergentes ou em transição, empresas possam enfrentar escassez e, até mesmo, obsolescência de recursos. 
Estratégia em negócios internacionais: evidência em uma trading company que atua entre economias emergentes

Assim, onde os recursos eram antes valiosos sob um regime de governo tornam-se menos valiosos no âmbito de instituições mais orientadas para o mercado. Desse modo, arranjos organizacionais, tais como grupos empresariais (conglomerados) e redes interorganizacionais, podem se manifestar em economias emergentes como uma forma de adaptação para lidar com os problemas de instituições do mercado subdesenvolvidas. No entanto, como as economias emergentes se movem em direção ao sistema de mercado, as redes pertencentes a tais sistemas econômicos podem precisar se reestruturar, a fim de acessar os recursos e capacidades necessárias para ter sucesso em um ambiente mais competitivo e dinâmico (PENG; ZHOU, 2005; OLIVER, 1997) necessitam, então, de capacidades dinâmicas (TEECE et al, 1997) que lhes permitam renovar/reconfigurar competências para atingir congruência com o ambiente empresarial em mutação.

A visão baseada em instituições ressalta as estruturas formais ou informais que regulam o desenvolvimento de negócios e podem moldar a competição industrial, bem como os recursos e as capacidades da firma (PENG et al., 2008; PENG; PLEGGENKUHLEMILES, 2009). As dimensões das instituições podem ser visualizadas no Quadro 1, desdobradas em níveis de formalização (NORTH,1990) e em pilares (SCOTT,1995) e operacionalizadas, respectivamente, como regras, leis, regulamentos e como normas de grupos, valores culturais, e cognição influenciada por etnia, religião e educação.

Quadro 1- Dimensões das instituições.

\begin{tabular}{|c|c|l|}
\hline Formalização (NORTH, 1990) & Pilares (SCOTT, 1995) & Operacionalização \\
\hline \multirow{2}{*}{ Formais } & Regulação (coersão) & $\begin{array}{l}\text { Regras } \\
\text { Leis } \\
\text { Regulamentos }\end{array}$ \\
\hline \multirow{2}{*}{ Informais } & Normatização & $\begin{array}{l}\text { Normas de grupos } \\
\text { Valores culturais }\end{array}$ \\
& Cognição & $\begin{array}{l}\text { Etnia } \\
\text { Religião } \\
\text { Educação }\end{array}$ \\
\cline { 2 - 3 } & & Scott \\
\hline
\end{tabular}

Fonte: Adaptado de North (1990) e Scott (1995).

\section{PROCEDIMENTOS METODOLÓGICOS}

A finalidade do presente trabalho pode ser considerada exploratório-descritiva, tendo como referência Tripodi, Fellin e Meyer (1975). Enquadra-se como estudo de caso (Yin, 2001) com abordagem qualitativa (Miles; Huberman, 1994; DOZ, 2011).

REAd I Porto Alegre - Edição 74 - № 1 - jan/abr 2013 - p. 219-246 
Birkinshaw, Brannen e Tung (2011) revelam que estudos qualitativos têm papel proeminente no enriquecimento do campo de estudos de negócios internacionais, contudo, a partir da década de 1990, perderam espaço para trabalhos quantitativos. Os autores veem que os métodos qualitativos vêm retomando lugar e este fato se deve à possibilidade de cobrir um conjunto de técnicas que podem descrever, decodificar, traduzir e chegar a um significado que não é expresso em frequência, capturando, dessa forma, fenômenos orgânicos do ambiente internacional de negócios (WELCH et al, 2011; DOZ, 2011).

A trading company estudada foi escolhida por apresentar operações majoritariamente (aproximadamente $90 \%$ do total) entre economias emergentes que oferecem um quadro diferente do campo de negócios internacionais (PENG et al., 2008; PENG; PLEGGENKUHLE-MILES, 2009; WRIGHT et al. 2005; MEYER; PENG, 2005), ter atuação em negócios internacionais consolidada (cerca de 25 anos), ser um caso de sucesso em negócios internacionais entre economias emergentes e mostrar receptividade para fornecer dados à pesquisa. A empresa movimentou, ao longo do ano de 2010, valores próximos a US\$ 60 milhões de dólares em transações por mês.

A pesquisa foi realizada em quatro etapas descritas no Quadro 2, ao longo dos meses de julho de 2010 a janeiro de 2011.

Quadro 2- Etapas da pesquisa.

\begin{tabular}{|c|c|c|}
\hline $1^{\mathrm{a}}$ Etapa & Análise Documental & $\begin{array}{l}\text { Análise documental envolvendo aproximadamente seis mil contratos } \\
\text { de compra e venda da trading company, a intenção nesta etapa foi a) } \\
\text { identificar produtos transacionados, bem como centros de origem de } \\
\text { fornecedores e compradores, b) contextualizar o pesquisador quanto } \\
\text { as atividades desempenhadas e c) dar sustentação inicial a formulação } \\
\text { das entrevistas. }\end{array}$ \\
\hline $2^{\mathrm{a}}$ Etapa & Primeira entrevista & $\begin{array}{l}\text { Abordou o tema do negócio da trading company, fizeram-se } \\
\text { perguntas abertas e contextuais quanto a motivos e razões para } \\
\text { transações com produtos e fornecedores/clientes levantados na análise } \\
\text { documental bem como as estratégias organizacionais utilizadas para } \\
\text { realizar tais transações. Três analistas foram entrevistados } \\
\text { pessoalmente no Brasil e dois pessoalmente na Rússia. }\end{array}$ \\
\hline $3^{\text {a }}$ Etapa & $\begin{array}{l}\text { Análise de conteúdo } \\
\text { da primeira entrevista }\end{array}$ & $\begin{array}{l}\text { Agrupou-se os motivos e razões para transações com produtos e } \\
\text { fornecedores/clientes com base nas pernas de sustentação estratégica } \\
\text { de Peng, Wang e Jiang (2008). }\end{array}$ \\
\hline $4^{\mathrm{a}}$ Etapa & Segunda entrevista & $\begin{array}{l}\text { Abordou o tema motivos e razões bem como as estratégias } \\
\text { organizacionais categorizados pela análise de conteúdo da primeira } \\
\text { entrevista, em situações dissonantes entre os entrevistados. A } \\
\text { intenção da segunda entrevista foi triangular as informações para que } \\
\text { o pesquisador toma-se conhecimento da situação real passada pela } \\
\text { firma. A segunda entrevista foi realizada via voz sobre IP (voice over } \\
\text { internet protocol - voip) com os mesmos entrevistados da } 2^{\mathrm{a}} \text { etapa. }\end{array}$ \\
\hline
\end{tabular}

Fonte: Resultado de Pesquisa

REAd I Porto Alegre - Edição 74 - N 1 - jan/abr 2013 - p. 219-246 
Estratégia em negócios internacionais: evidência em uma trading company que atua entre economias emergentes

Para a coleta dos dados primários, lançou-se mão de um roteiro de entrevistas semiestruturadas baseada em questões abertas que levaram em consideração as pernas de sustentação estratégica de Peng, Wang e Jiang (2008).

As entrevistas foram feitas em inglês com os cinco analistas de negócios da referida trading company, sendo conduzida segundo as indicações de Miles e Huberman (1994), as categorias e subcategorias de análise desenvolvidas no estudo encontram-se em Apêndice. Os analistas de negócios também são parte detentora da propriedade da trading company estudada, o perfil dos analistas é feito no Quadro 3, bem como o tempo e o numero de entrevistas realizada com cada um.

Quadro 3 - Perfil da coleta dos dados primários.

\begin{tabular}{|c|c|c|c|c|c|}
\hline & Analista A & Analista B & Analista $\mathrm{C}$ & Analista D & Analista E \\
\hline Idade & 62 & 55 & 52 & 40 & 43 \\
\hline $\begin{array}{l}\text { Tempo na firma } \\
\text { (anos) }\end{array}$ & 25 & 25 & 23 & 11 & 10 \\
\hline $\begin{array}{l}\text { Tempo de duração da } \\
1^{\mathrm{a}} \text { entrevista } \\
\left(2^{\mathrm{a}} \text { etapa da pesquisa) }\right.\end{array}$ & $2 \mathrm{~h}$ e $35^{\prime}$ & $2 \mathrm{~h}$ e $15^{\prime}$ & $1 \mathrm{~h}$ e $30^{\prime}$ & $1 \mathrm{~h}$ e $55^{\prime}$ & $1 \mathrm{~h} \mathrm{e} 40^{\prime}$ \\
\hline $\begin{array}{l}\text { Tempo de duração da } \\
2^{\mathrm{a}} \text { entrevista } \\
\text { ( } 4^{\mathrm{a}} \text { etapa da pesquisa) }\end{array}$ & $30^{\prime}$ & $25^{\prime}$ & $30^{\prime}$ & $25^{\prime}$ & $25^{\prime}$ \\
\hline
\end{tabular}

Fonte: Resultado de Pesquisa.

Para analisar e interpretar os dados colhidos foi utilizada a técnica da análise de conteúdo (MILES; HUBERMAN, 1994). Com esta técnica identificaram-se tópicos comuns relacionados ao entendimento dos direcionadores da estratégia e o fator determinante de sucesso da referida firma em negócios internacionais ao longo de sua trajetória. Esta técnica foi escolhida por ser reconhecida como válida e de largo emprego em estudos qualitativos (MILES; HUBERMAN, 1994; WELCH et al, 2011; DOZ, 2011).

\section{ANÁLISE E DISCUSSÃO DOS DADOS}

Tratamos, a seguir, da trajetória e do desempenho da empresa estudada, assim como da identificação dos fatores direcionadores de sua estratégia, vistos pelas lentes de competição industrial, visão baseada em recursos e visão baseada em instituições. 
Karim Marini Thomé, Janann Joslin Medeiros \& Cristina Lélis Leal Calegário

\subsection{Caracterização da trading company e de seu negócio: trajetória e atual performance}

A firma estudada foi fundada em 1986, na Holanda e um resumo de sua trajetória pode ser visto na Figura 3. Suas atuações iniciais eram baseadas no comércio de flores e queijos holandeses para outros países da Europa Ocidental, com destaque para França, Itália e Alemanha. Nesta fase, a trading company atuava como atravessador, adquirindo os produtos no seu centro de origem e revendendo-os em outros mercados, tais como os referidos anteriormente.

1986

1991

1996

2001

2006

2011

\begin{tabular}{|c|c|c|c|c|c|}
\hline $\begin{array}{l}\text { Início das } \\
\text { atividades no } \\
\text { comércio de } \\
\text { flores e } \\
\text { queijos. } \\
\text { Retirada das } \\
\text { atividades no } \\
\text { setor de } \\
\text { queijo e novo } \\
\text { foco no setor } \\
\text { de flores. } \\
\text { Novos } \\
\text { fornecedores, } \\
\text { na África e } \\
\text { na América } \\
\text { Central. }\end{array}$ & $\begin{array}{l}\text { Iniciam } \\
\text { operações } \\
\text { com novos } \\
\text { produtos } \\
\text { agrícolas, nos } \\
\text { mesmos } \\
\text { países } \\
\text { fornecedores. } \\
\text { Conquista de } \\
\text { novos } \\
\text { clientes da } \\
\text { Europa } \\
\text { Ocidental. }\end{array}$ & $\begin{array}{l}\text { Conquista de } \\
\text { novos } \\
\text { fornecedores } \\
\text { da América } \\
\text { do Sul e da } \\
\text { Europa } \\
\text { Oriental. } \\
\text { Expansão via } \\
\text { aquisição de } \\
\text { tradings. } \\
\text { Entrada no } \\
\text { mercado de } \\
\text { carnes. } \\
\text { Criação de } \\
\text { centros de } \\
\text { negócio. }\end{array}$ & $\begin{array}{l}\text { Começo de } \\
\text { transações } \\
\text { entre clientes } \\
\text { e } \\
\text { fornecedores } \\
\text { de economias } \\
\text { emergentes. } \\
\text { Início de } \\
\text { operações } \\
\text { comerciais } \\
\text { com clientes } \\
\text { no Oriente } \\
\text { Médio. }\end{array}$ & $\begin{array}{l}\text { Entrada no } \\
\text { mercado } \\
\text { Asiático. } \\
\text { Aumento de } \\
\text { transações } \\
\text { envolvendo } \\
\text { economias } \\
\text { emergentes. } \\
\text { Saída do } \\
\text { setor de } \\
\text { flores. }\end{array}$ & $\begin{array}{l}\text { Saída do } \\
\text { mercado } \\
\text { Asiático. } \\
\text { Concentração } \\
\text { de operações } \\
\text { em } \\
\text { economias } \\
\text { emergentes. } \\
\text { Possui } 4 \\
\text { centros de } \\
\text { negócios e } 36 \\
\text { pessoas } \\
\text { envolvidas } \\
\text { diretamente. }\end{array}$ \\
\hline
\end{tabular}

Figura 3 - Trajetória simplificada como linha do tempo da trading company estudada, em quinquênios. Fonte: Resultado de Pesquisa.

Com menos de seis meses de atuação, a firma estudada retirou-se do mercado de queijos e permaneceu apenas no setor de flores. De acordo com os respondentes, o primeiro desafio encontrado pela empresa em questão era com relação ao seu posicionamento no mercado. Os mercados de queijos e flores, na visão dos respondentes, apresentavam-se em movimento de estruturação, com a integração vertical de grandes empresas por parte dos fornecedores e clientes, ou seja, dos antigos produtores e varejistas europeus desses produtos.

A estratégia escolhida para enfrentar esta situação foi sair do setor de queijos e direcionar-se a setores de flores menos competitivos, especificamente o de flores tropicais. É evidenciado na entrevista que a intenção com este posicionamento era entrar em um segmento no qual a firma estudada pudesse fornecer produtos diferenciados dos encontrados nos 
Estratégia em negócios internacionais: evidência em uma trading company que atua entre economias emergentes

mercados europeus naquela época, procurando novos fornecedores, fora da rota normal de produtores holandeses.

Com o conhecimento de clientes varejistas no ramo florista e a identificação de oportunidades no nicho de flores tropicais, a empresa passou a procurar e selecionar novos fornecedores que tivessem disponibilidade de produtos. Os fornecedores foram encontrados em três países africanos e dois países centro-americanos, totalizando, assim, onze pequenos e médios produtores de flores tropicais, que apresentavam as características desejadas pela trading company.

Até o momento, percebe-se que fatores preconizados pela abordagem de estrutura industrial (PORTER, 1985), tais como poder de barganha de fornecedores e clientes, e pressões concorrenciais, foram determinantes para a estratégia de atuação da firma. Passagens da entrevista apenas tomam conotações institucionais a partir do momento que a trading company passa a negociar e a transacionar com fornecedores externos à Europa.

Pela perspectiva institucional, a principal dificuldade encontrada pela trading company dizia respeito a critérios formais da regulação institucional, ou seja, leis e regras que envolviam as transações diferentes daquelas com as quais a firma estava acostumada a lidar. Como alternativa para contornar, nas palavras de um dos respondentes, “(...) diversas incompreensões", eram utilizados interlocutores locais, para diminuir os problemas ocasionados pela assimetria institucional e permitir a maior fluidez das negociações e do comércio.

A trajetória organizacional começa a evidenciar o desenvolvimento de recursos e capacidades organizacionais necessárias para efetuação de negócios em ambientes institucionais diferenciados, sobretudo em conhecimento tácito de como lidar com ambiente diferente ao que deu origem a firma. A formação desse conhecimento é indicada pelos respondentes como de grande importância para que a trading company inicie operações com outros produtos, também do setor agrícola, envolvendo outros fornecedores nos mesmos países africanos e centro-americanos.

Com a possibilidade de fornecimento de novos produtos, um cliente varejista que já apresentava histórico de transação acabou por redirecionar a firma estudada, em função de atividades de fornecimento para as suas subsidiárias periféricas ao país de sua matriz que se localizava no Reino Unido e, assim, entrou em novos mercados (Portugal, Espanha e Irlanda)

REAd I Porto Alegre - Edição 74 - Nº 1 - jan/abr 2013 - p. 219-246 
Karim Marini Thomé, Janann Joslin Medeiros \& Cristina Lélis Leal Calegário

utilizando a rede de atuação de seu cliente que, por sua vez, impulsionou novo desenvolvimento de conhecimento tácito nestes mercados.

A importância da rede de negócios fica acentuada na fala dos entrevistados e esta trajetória confirma a possibilidade de entrar em mercados pela rede de clientes e/ou fornecedores mencionada por Johanson e Vahlne (2009), traçando, desse modo, linhas de evolução conforme citado por Håkansson e Snehota (1995).

Entre os anos de 1996 e 2001, novos fornecedores foram prospectados devido ao conhecimento de oportunidades de negócios dos então clientes na Europa Ocidental. Percebese, pelas entrevistas, que a trading company apresenta a capacidade de captar conhecimento de sua rede. Houve também a aquisição de outras duas trading companies que já atuavam em mercado da América do Sul e da Europa Oriental. Esta diversificação de países de atuação foi simultânea ao processo de expansão internacional de empresas varejistas e, até mesmo, de indústrias processadoras descritas por Ellis (2001) e evidenciadas também neste estudo. Desse modo, pela própria conjuntura de mercado, a firma estudada passou a ter clientes em economias emergentes, quando anteriormente eram exclusivamente de economia desenvolvida, abrindo, assim, a possibilidade de triangular negócios entre economias emergentes. Este fato, de acordo com as entrevistas, só se tornou possível pela experiência antecedente de transações desenvolvidas pela trading company com clientes varejistas e fornecedores, assim como descrito por Lages e Montgomery (2004).

Assim como mencionado por Dunning e Lundan (2008), a internacionalização de empresas ou, até mesmo, a atuação de multinacionais pode apresentar problemas de operações em economias emergentes. Os entrevistados comentaram que a trading company estudada percebeu que empresas varejistas que tiveram o processo de expansão internacional em economias emergentes esbarraram em dificuldades, sobretudo em fatores institucionais, assim como mencionado por Peng et al. (2008). O entendimento dessa situação se tornou fator decisivo para que a trading company iniciasse a atuação também como um agente comissionado. Desse modo, a firma estudada passava a executar as duas formas de atuação em triad descritas por Havila et al. (2004).

Outro fator que contribuiu para a decisão de atuação como comissionado, lembrado por um dos entrevistados, foi o fato de que os valores/volumes transacionados inicialmente entre mercados emergentes eram extremamente altos, já que poucas empresas estavam operando nesse mesmo sentido comercial. Desse modo, a situação de mercado era de 
Estratégia em negócios internacionais: evidência em uma trading company que atua entre economias emergentes

concentração nas transações que refletia em altos valores, incompatíveis com o capital da organização naquele momento.

O incremento no volume das transações foi tamanho que impulsionou a formalização de cinco centros de negócios $(\mathrm{CN})$ - na América do Sul, Oriente Médio, Europa Oriental, Hong Kong e África, respectivamente - pela firma estudada. De acordo com os entrevistados, estes CN tinham a finalidade de aumentar a interação de informações entre portfólios de clientes e fornecedores, dar continuidade à proximidade nas relações institucionais da trading company nas operações de exportação e importação e manter os recursos humanos, recursos estes que são reconhecidos pelos entrevistados como os detentores de conhecimento tácito desenvolvido pela firma.

Atualmente, a firma não conta mais com o CN Hong Kong. A justificativa dada para o fechamento deste $\mathrm{CN}$ se relaciona ao fato de a firma apresentar insuficiência de escala de negócios, bem como a insucesso no estabelecimento das relações institucionais (formais e/ou informais) necessárias para sustentar as relações de negócios no respectivo mercado, como descritos por Peng e Zhou (2005).

A trading company conta com cinco analistas que percorrem constantemente os $\mathrm{CN}$, onze consultores responsáveis pela prospecção de novos clientes e fornecedores, bem como manutenção e desenvolvimento do relacionamento com os atuais. Os consultores, diferentemente dos analistas, permanecem fixos no $\mathrm{CN}$ de sua contratação. O CN com menor número de consultores é o do Oriente Médio, com dois. Os demais mantêm três. Por fim, há vinte operadores incumbidos de realizar operações de transações comerciais, cerca de cinco por $\mathrm{CN}$ e fixos.

Como mencionado, a firma lida majoritariamente com negócios entre mercados emergentes (aproximadamente 90\%) e, no ano de 2010, realizou média mensal de U\$ 60 milhões em transações. Encontra-se, atualmente, operando com 27 produtos, destacando-se carne bovina e de cordeiro, trigo, madeira, açúcar, batata e maçã, e em 32 países, sobretudo Brasil, Argentina, Rússia, África do Sul, Venezuela, Nigéria, Irã e Emirados Árabes Unidos.

\subsection{Competitividade industrial}

De acordo com a própria natureza do negócio das trading companies, observa-se que, ao longo de sua trajetória, a estratégia da firma estudada apresentou características 
Karim Marini Thomé, Janann Joslin Medeiros \& Cristina Lélis Leal Calegário

consistentes com direcionadores preconizados pela abordagem de competitividade industrial. Impulsionada por situações limitantes à sua atuação ou por oportunidade de negócios, lançou mão de diversas estratégias organizacionais, como ilustrado no Quadro 4.

Quadro 4 - Estratégias organizacionais utilizadas ao longo da trajetória da trading company.

\begin{tabular}{|c|c|c|c|}
\hline Motivo & $\begin{array}{l}\text { Referência acadêmica } \\
\text { que aborda o motivo }\end{array}$ & Estratégia organizacional & Ano \\
\hline \multirow{3}{*}{$\begin{array}{l}\text { Pressões de } \\
\text { clientes, } \\
\text { fornecedores e } \\
\text { concorrentes }\end{array}$} & \multirow{3}{*}{$\begin{array}{l}\text { Porter (1985); Ellis } \\
\text { (2001); Coughlan, } \\
\text { Stern et al. }(2002) \mathrm{e} \\
\text { Jones }(1998) .\end{array}$} & $\begin{array}{l}\text { Retirada do setor de queijos e redirecionamento } \\
\text { no setor de flores ao segmento de flores tropicais. }\end{array}$ & 1986 \\
\hline & & $\begin{array}{l}\text { Retirada do mercado asiático e concentração nos } \\
\text { centros de negócios restantes }\end{array}$ & 2010 \\
\hline & & $\begin{array}{l}\text { Redirecionamento para fornecedores de produtos } \\
\text { demandados em outras regiões do globo, } \\
\text { obtenção de } 11 \text { pequenos/médios produtores } \\
\text { (rendimento de cada fornecedor inferior a U\$ } 50 \\
\text { mil ao ano). }\end{array}$ & 1986 \\
\hline \multirow{3}{*}{$\begin{array}{l}\text { Ganho de } \\
\text { escopo }\end{array}$} & \multirow{3}{*}{$\begin{array}{l}\text { Porter (1985); } \\
\text { Coughlan, Stern } \text { et al. } \\
\text { (2002) e Ellis (2001) }\end{array}$} & $\begin{array}{l}\text { Diversificação de produtos e diversificação } \\
\text { geográfica de clientes e de fornecedores }\end{array}$ & $\begin{array}{l}\text { 1986, } 1987 \\
\text { e } 1990\end{array}$ \\
\hline & & Diversificação de função & 2002 \\
\hline & & $\begin{array}{l}\text { Diversificação de geografia (clientes), em } \\
\text { mercado do Oriente Médio e asiático. }\end{array}$ & 2001 e 2007 \\
\hline \multirow{2}{*}{ Ganho de escala } & \multirow{2}{*}{$\begin{array}{c}\text { Porter (1985); } \\
\text { Coughlan, Stern } \text { et al. } \\
\text { (2002) e Ellis (2001) }\end{array}$} & $\begin{array}{l}\text { Ampliação das transações com agentes que } \\
\text { apresentavam histórico de transações. }\end{array}$ & $\begin{array}{l}1997,2003 \\
2007 \text { e } 2010\end{array}$ \\
\hline & & Aquisição de outras trading companies & 1998 \\
\hline
\end{tabular}

Fonte: Resultado de Pesquisa.

Os motivos acima referidos tratam-se, sobretudo, de pressões exercidas por fornecedores, clientes e concorrentes, bem como ganhos de escala e escopo. Estes fatores direcionadores podem ser explicados pela estrutura dos mercados em que a trading company se localizava e que se traduziram em estratégias organizacionais utilizadas na tentativa de permanecer e obter sucesso em seu negócio.

\subsection{Recursos e capacidades da firma}

Menção das capacidades e recursos da firma apenas começou a aparecer nas entrevistas a partir do momento em que se tocou no início das atividades voltadas a países centro-americanos e africanos, na tentativa de prospectar novos fornecedores para clientes REAd I Porto Alegre - Edição 74 - N 1 - jan/abr 2013 - p. 219-246 
Estratégia em negócios internacionais: evidência em uma trading company que atua entre economias emergentes

europeus. Durante a trajetória da firma, podem-se notar várias mudanças estratégicas, algumas vezes condicionadas a momentos de dificuldades e grandes pressões e outras respondendo a oportunidades. Na maioria das situações, as mudanças foram ocasionadas por uma demanda no ambiente externo. Para manter-se competitiva, teve de desenvolver, por diversas vezes, estratégias emergentes e precisou adequar seus objetivos a novas demandas por meio do desenvolvimento de novas competências, como a capacidade de lidar com ambientes de transição institucional e a intermediação de transações em mercados emergentes, visando à competitividade ou à perpetuação de seu negócio.

Evidenciam-se no discurso dos entrevistados elementos tais como conhecimento tácito (em duas entrevistas) e capital social/rede de negócios (todos os entrevistados), mencionados por Johanson e Vahlne (2009), Peng (2001), Dyer e Singh (1998) e Håkansson e Snehota (1995), que podem ser caracterizados como recursos competitivos utilizados na gestão do negócio da trading company estudada. Estes recursos competitivos foram consolidados e expandidos ao longo da trajetória organizacional, de maneira que permitissem a perpetuação dos negócios da firma e possibilitassem a sua expansão. Cada movimento, entrada/saída/expansão/retração, de atividades e operações em mercados internacionais tinha particularidades relacionadas ao nível de conhecimento dos analistas, consultores e operadores.

Há evidências do desenvolvimento, ao longo do tempo, de uma capacidade dinâmica da firma, que mostra evolução condicionada à aprendizagem adquirida na trajetória organizacional e às mudanças enfrentadas no ambiente competitivo de negócios internacionais. Desse modo, as capacidades dinâmicas criadas e desenvolvidas pela firma estudada ilustram bem a dependência de percurso (path dependence) que produz expertise em um determinado negócio. É difícil de ser imitada pelos concorrentes e é capaz de gerar vantagem competitiva ao seu detentor, assim como mencionado por Peng (2001).

Por duas vezes, as entrevistas apontaram as capacidades da firma como geradoras de vantagens para seu detento. A primeira passagem relata a situação que impulsionou a saída da firma estudada do mercado de queijos na Europa Ocidental, ainda no ano de 1986. Este episódio, de acordo com os entrevistados, se deveu às capacidades superiores dos concorrentes naquele mercado, deixando a trading company estudada em desvantagem. $\mathrm{O}$ outro evento diz respeito ao ganho de escala, derivado da rede de negócios, dos clientes varejistas que se internacionalizaram e necessitavam de fornecimento em novas localidades 
Karim Marini Thomé, Janann Joslin Medeiros \& Cristina Lélis Leal Calegário

geográficas, sendo necessária a expansão dos serviços da firma estudada para as então novas subsidiárias estabelecidas por aquele cliente varejista. Caracteriza-se aqui a importância da capacidade relacional que resulta no que Johanson e Vahlne (2009) chamam de expansão de mercado para mercado, utilizando a rede de negócios de clientes.

Com a intenção de encontrar a menor unidade que se expressa o recurso competitivo aqui descrito, chegou-se à atuação das pessoas que executam e operam os negócios internacionais que estão situadas na firma estudada. De acordo com as entrevistas, analistas, consultores e operadores carregam o conhecimento tácito criado pela organização e, em muitas ocasiões, são identificadas como imagem da própria trading company frente à sua rede de negócios. A firma, no intuito de evitar fuga de conhecimento tácito e, até mesmo, manter representatividade frente à rede de negócios, procura formar e reter recursos humanos.

\subsection{Condições e transições institucionais}

Logo com a primeira mudança de fornecedores holandeses para fornecedores centroamericanos e africanos, a firma se defrontava com as dificuldades de lidar com diferenças institucionais. As diferenças mais imediatamente notadas foram em âmbito institucional formal/regulatório relacionado a leis, regras e regulamentos de formalização da transação (atributos contratuais) e com a burocracia envolvida no ato da exportação.

Em outras situações, o nível institucional formal/regulatório estabelecia limitações ao negócio da trading company, apresentando barreiras técnicas ao comércio internacional de alimentos do tipo descrito por Henson e Loader (2001). Tais normas acabam vedando ou limitando o comércio internacional de alguns produtos transacionados pela firma estudada, afetando negativamente os negócios de clientes da firma radicados em países onde vigoram tais barreiras. Um exemplo seria o caso da carne bovina brasileira in natura que era transacionado com clientes em países da Europa Ocidental.

As instituições formais/regulatórias encontradas foram classificadas, pelos entrevistados, em dois tipos: as imutáveis e as flexíveis. As imutáveis são as leis fixas que independem da atuação da trading company. Por exemplo: a Argentina sobretaxa em "X"\% o valor do açúcar bruto de cana brasileiro que entra naquele país. Já as flexíveis dizem respeito a processos/trâmites burocráticos decorrentes da exportação que admitem interferência de ação por parte da trading company, como no caso de emissão de guia para importação de trigo

REAd I Porto Alegre - Edição 74 - № 1 - jan/abr 2013 - p. 219-246 
Estratégia em negócios internacionais: evidência em uma trading company que atua entre economias emergentes

argentino por organizações que pretendem trazê-lo ao Brasil. Tais guias podem demorar dias para serem emitidas, contudo, com ações informais, a trading company estudada consegue obtê-las em 3 horas, ou seja, a situação pode ser influenciada por capacidades organizacionais que interferem em instituições informais.

O fenômeno mencionado é analisado por Peng e Luo (2000) e caracterizado como micro-macro link, e é tido como normal em economias emergentes (PENG, 2003). Este micro-macro link seria, então, uma ligação em um baixo nível de representatividade - como o relacionamento interpessoal - que reflete em um alto nível de atuação, por exemplo, relacionamento inter-organizacional, performance e proximidade público-privada.

Instituições informais (NORTH, 1990), normativas e cognitivas (SCOTT, 1995) também foram analisadas e, pelo posicionamento dos respondentes, apresentam tanta ou até mais importância que as instituições formais/regulatórias, pois, muitas vezes, os limites de atuação por elas estabelecidos não estão expressos ou claros. Muitas vezes, as instituições informais, no sentido mais amplo de North (1990), podem causar acréscimo de dificuldades nas interconexões realizadas pela trading company. Um exemplo disso são os clientes varejistas que atuam no Irã e, devido a motivos religiosos, demandam carne bovina brasileira e ovina argentina produzida por um sistema diferenciado de abate, realizado por muçulmanos. Outro é o caso dos grupos de interesse que atuam em Hong Kong, na Rússia e no Brasil, e podem criar situações crônicas para o negócio da trading company devido à sua representatividade frente a instituições informais. Como foram apreciadas, as dificuldades em lidar com instituições informais desse tipo, relativamente comuns em economias emergentes, motivaram a retirada do $\mathrm{CN}$ Hong Kong da firma estudada.

Contudo, quando a firma consegue, com seus recursos e capacidades, gerenciar as interfaces com as instituições informais e aos ambientes competitivos, percebeu-se que há a construção de um envolvimento de proximidade entre as partes, que se torna difícil rompê-lo. Conforme revelam as evidências colhidas, a trading company estudada traz, em sua rede de negócios, relacionamentos que não se restringem apenas a agentes comerciais, impulsionada por exigências das instituições formais e informais que moldam e permeiam o ambiente de negócios em economias emergentes. Observa-se, assim, como, na prática, pode funcionar a interação de recursos da firma com fatores institucionais, postulada por Oliver (1997). Ficou evidenciado que as instituições, sim, têm poder de influenciar a firma estudada, mas que a 
Karim Marini Thomé, Janann Joslin Medeiros \& Cristina Lélis Leal Calegário

firma também consegue modificar e selecionar seu ambiente de negócios, a incluir o ambiente institucional.

\section{CONSIDERAÇÕES FINAIS}

O presente estudo objetivou investigar o que direciona a estratégia de uma trading company e o que determina o sucesso da mesma em negócios internacionais. Contudo, não foi possível nominar, dentre os fatores descritos por Peng et al. (2008), um único direcionador da estratégia da trading company estudada. O que se pode notar é uma variedade de estratégias baseadas ora em competitividade industrial, ora em recursos e capacidades da firma e ora em condições institucionais. Cada direcionador correspondeu, assim, em um determinado momento, a um norteador estratégico na trajetória da trading company estudada. Da mesma maneira, não foi observada uma ordem cronológica linear entre os direcionadores, tampouco a sua obsolescência. Ao contrário, as evidências apontam que os direcionadores são cumulativos e cíclicos, ou seja, podem necessitar ser revisados e, até mesmo, repensados, em função de atributos organizacionais e do contexto ambiental, que se modificam.

O determinante de sucesso da mesma em negócios internacionais entre economias emergentes foi considerado aqui como a capacidade da firma de gerenciar as interfaces entre os fatores de competitividade industrial, recursos e capacidades e das condições e transições institucionais. Esta capacidade possibilitou, assim, que a firma estudada se sobressaísse nas adversidades e explorasse oportunidades de negócios em diferentes partes do globo.

Conclui-se que o resgate de North (1990) e Scott (1995), proposto por Peng et al. (2008), é válido para explicar o ambiente de negócios da trading company estudada e suas possíveis interações organizacionais decorrentes. As sugestões que se fazem para estudos futuros dizem respeito às interações entre os fatores estratégicos utilizados em economias emergentes, criando e desenvolvendo interconexões de fatores que possam explicar o sucesso ou o fracasso de firmas em detrimento de seu ambiente de negócios escolhido. Por fim, espera-se que este artigo fomente a discussão a respeito da estratégia e da atuação de trading companies, bem como de outras formas organizacionais que atuem entre economias emergentes.

Finalmente, cabe observar que o método utilizado não permite a extrapolação das análises para todo o universo de trading companies que atuam em economias emergentes, restringindo, desse modo, as conclusões ao caso estudado.

REAd I Porto Alegre - Edição 74 - № 1 - jan/abr 2013 - p. 219-246 
Estratégia em negócios internacionais: evidência em uma trading company que atua entre economias emergentes

\section{REFERÊNCIAS}

ANTRÀS, P.; COSTINOT, A. Intermediated trade. The Quarterly Journal of Economics, vol. 126, n. 3, p.1319-1374, 2011.

AHN, J. KHANDELWAL, A. K. WEI, S.-J. The role of intermediaries in facilitating trade. Journal of International Economics, vol. 84, n. 1, p. 73, 2011.

AIDIS, R.; ADACHI, Y. Russia: firm entry and survival barriers. Economic Systems, vol. 31, n. 4, p.391-411, 2007.

ACHROL, R. S. Evolution of marketing organization: new forms for turbulent environment. Journal of Marketing, vol. 55, p.77-93, 1991.

BARNEY, J. B. Firm resources and sustainable competitive advantage. Journal of Management, vol. 17, n.1, p.99-121, 1991.

BARNEY, J.; WRIGHT, M.; KETCHEN, D. The resource-based view of the firm: ten years after 1991. Journal of Management, vol. 27, 625-641, 2001.

BIGGESMANN, S.; FAM, K.-S. Business marketing in BRIC countries Industrial Marketing Management, vol. 40, p.5-7, 2011.

BIRKINSHAW, J.; BRANNEN, M. Y.; TUNG, R. L. From a distance and generalize to up close and grounded: reclaiming a place for qualitative methods in international business research. Journal of International Business Studies, n. 42, p.573-581, 2011.

CHINTAKANANDA, A.; YORK, A. S.; O`NEIL, H. M.; PENG, M. W. Structuring dyadic relationships between export producers and intermediaries. European Journal of International Management, vol. 3 n.3, p.302-327, 2009.

COUGHLAN, A.T.; ANDERSON, E.; STERN, L. W.; El-ANSARY, A. I. Canais de Marketing e Distribuição. ed.6. Porto Alegre: Bookman, 2002.

REAd I Porto Alegre - Edição 74 - Nº 1 - jan/abr 2013 - p. 219-246 
Karim Marini Thomé, Janann Joslin Medeiros \& Cristina Lélis Leal Calegário

DOZ, Y.Qualitative research for international business. Journal of International Business Studies, vol. 42, p.582-590, 2011.

DUNNING, J. H.; LUNDAN, S. M. Institution and the OLI paradigm of the multinational enterprise. Asia Pacific Journal Management, vol. 25, p.573-593, 2008.

DYER, J. H.; SINGH, H. The relational view: cooperative strategy and sources of interorganizational competitive advantage. Academy of Management Review, vol. 23, n. 4, p.660-679, 1998.

EASTON, G. Industrial networks: a review. In. AXELSSON, B.; EASTON, G. (Eds.). Industrial networks: A new view of reality London: Routledge, p. 1-27, 1992.

ESTRIN, S; PREVEZER, M. A survey on institutions and new firm entry: how and why do entry rates differ in emerging markets?. Economic Systems, vol. 34, n. 3, p. 289-308, 2010.

ELLIS, P. D. Adaptative Strategies of trading companies. International Business Review, vol. 10, n.2, p.235-259, 2001.

FARUQ, H. How institutions affect export quality. Economic Systems, vol. 35, n. 4, p. 586606, 2011.

FUNG, P. K. O.; CHEN, I. S. N.; YIP, L. S. C. Relationships and performance of trade intermediaries: an exploratory study. European Journal of Marketing, vol. 41, n. 1, p.159$180,2007$.

GRANOVETTER, M. S. The Strenght of Weak Ties. American Journal of Sociology, vol.78, n. 6, p.1360-1380, 1973.

HAVILA, V.; JOHANSON, J.; THILENIUS, P. International business: relationship triads. International Marketing Review, vol. 21, n. 2, p.172-186, 2004.

REAd I Porto Alegre - Edição 74 - Nº 1 - jan/abr 2013 - p. 219-246 
Estratégia em negócios internacionais: evidência em uma trading company que atua entre economias emergentes

HAKANSSON, H.; SNEHOTA, I. Developing relationships in business network. New York: Routledge, 1995.

HENSON, S.; LOADER, R. Barriers to agricultural exports from developing countries: the role of sanitary and phytosanitary requirements. World Development, vol. 29, n. 1, p.85-102, 2001.

JOHANSON, J.; VAHLNE, J.-E. The Uppsala internationalization process model revisited: from liability of foreignness to liability of outsidership. Journal of International Business Studies, vol. 40, p.1411-1431, 2009.

JONES, G. Multinational trading companies in history and theory. In JONES, G. The Multinational Traders. London: Routledge, p.1-21, 1998.

KEDIA, B.; GAFFNEY, N.; CLAMPIT, J. EMNEs and Knowledge-seeking FDI. Management International Review, vol. 52, p.155-173, 2012

LAGES, L. F.; MONTGOMERY, D. B. Export performance as an antecedent of export commitment and marketing strategy adaptation: evidence from small and medium-sized exporters. European Journal of Marketing, vol. 38, n. 9, p.1186-1214, 2004.

MADSEN, T. K.; MOEN, O. HAMMERVOLD, R. The role of independent intermediaries: the case of small and medium-sized exporters. International Business Review, vol. 21, p.535-546, 2012.

MARCHAN-PIEKKARI, R.; WELCH, C. Handbook of Qualitative Research Methods in International Business, Cheltenham: EdwardElgar, 2004.

MARTELL, L. The third wave in globalization theory. International Studies Review, vol. 9, p.173-196, 2007. 
Karim Marini Thomé, Janann Joslin Medeiros \& Cristina Lélis Leal Calegário

MEYER, K. E.; PENG, M. W. Probing theoretically into Central and Eastern Europe: transactions, resources and institutions. Journal of International Business Studies, vol. 36, p.600-621, 2005.

MILES, B. M.; HUBERMAN, A. M. Qualitative Data Analysis. ed. 2 Oaks, CA: Sage, 1994.

MILlS, J.; PLATTS, K.; BOURNE, M.; RICHARDS, H. Competing Through Competences. Cambridge: University Press, 2002.

NORTH, D. C. Institutions, institutional change, and economic performance. Cambridge, MA: Harvard University Press, 1990.

OLIVER, C. Sustainable competitive advantage: combining institutional and resource-based views. Strategic Management Journal, vol. 18, n. 9, p.679-713, 1997.

PENG, M. W. The resource-based view and international business. Journal of Management, vol. 27, n. 6, p.803-829, 2001.

PENG, M. W.; LUO, Y. Managerial ties and firm performance in a transition economy: the nature of a micro-macro link. Academy of Management Journal, vol. 43, p.486-501, 2000.

PENG, M. W.; YORK, A. S. Behind intermediary performance in export trade: transactions, agents, and resources. Journal of International Business Studies, vol. 32, n. 2, p.327-346, 2001.

PENG, M. W. Institutional transitions and strategic choices. Academy of Management Review, vol. 28, n.2, p.275-296, 2003.

PENG, M. W. Identifying the big question in international business research. Journal of International Business Studies, vol. 35, n. 2, p.99-108, 2004. 
Estratégia em negócios internacionais: evidência em uma trading company que atua entre economias emergentes

PENG, M. W.; ZHOU, J. Q. How network strategies and institutional transitions evolve in Asia. Asia Pacific Journal of Management, vol. 22, n. 4, p.321-336, 2005.

PENG, M. W.; ZHOU, Y.; YORK, A. S. Behind make or buy decisions in export strategy: a replication and extension of Trabold. Journal of World Business, vol. 41, n. 3, p.289-300, 2006.

PENG, M. W. Global strategy. Cincinnati: Thomson, 2006.

PENG, M. W.; WANG, D. Y. L.; JIANG, Y. An institution-based view of international business strategy: a focus on emerging economies. Journal of International Business Studies, vol. 39, n. 5, p.920-936, 2008.

PENG, M. W.; PLAGGENKUHLE-MILES, E. G. Current debates in global strategy. International Journal of Management Reviews, vol. 11, n.1, p.51-68, 2009.

PORTER, M. E. Estratégia competitiva: técnicas para analisar indústrias e seus competidores. Rio de Janeiro: Campus, 1985.

RAUCH, J. E. Business and social network in international trade. Journal of Economic Literature, vol. 39, p.1177-1203, 2001.

SCOTT, W. R. Institutions and organizations. Oaks, CA: Sage, 1995.

TEECE, D. J.; PISANO, G.; SHUNEN, A. Dynamic capabilities and strategic management. Strategic Management Journal, vol. 18, n. 7, p.509-533, 1997.

TRIPODI, T.; FELLIN, P.; MEYER, H. Análise da pesquisa social. Petrópolis: Alves, 1975. 
Karim Marini Thomé, Janann Joslin Medeiros \& Cristina Lélis Leal Calegário

WELCH, C.; PIEKKARI, R.; PLAKOYIANNAKI, E.; PAAVILAINEN-MÄNTYMÄKI, E. 2011. Theorising from case studies: Towards a pluralist future for international business research. Journal of International Business Studies, vol. 42, p.740-762, 2011.

WILLIAMSON, O. E. Comparative economic organization: the analysis of discrete structural alternatives. Administrative Science Quarterly, vol. 36, p.269-296, 1991.

WRIGHT, M.; FILATOTCHEV, I.; HOSKISSON, R. E.; PENG, M. W. Strategy research in emerging economies: challenging the conventional wisdom. Journal of Management Studies, vol. 42, n. 1, p.01-33, 2005.

YIN, R. K. Estudo de caso: planejamento e métodos. Porto Alegre: Bookman, 2001.

\section{Apêndice}

\begin{tabular}{|c|c|c|c|}
\hline & Categoria & Subcategoria & Frequência $(\%)$ \\
\hline \multirow{8}{*}{ 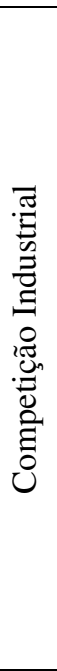 } & \multirow{4}{*}{$\begin{array}{l}\text { Pressão por clientes, } \\
\text { fornecedores e } \\
\text { competidores }\end{array}$} & Retirada se setores especificos & 100,0 \\
\hline & & Retirada de fornecedores e clientes & 100,0 \\
\hline & & Redirecionamento de fornecedores e clientes & 100,0 \\
\hline & & Retirada de mercados específicos & 80,0 \\
\hline & \multirow[b]{2}{*}{ Ganho de escopo } & Diversificação de produto e cobertura geográfica & 100,0 \\
\hline & & $\begin{array}{l}\text { Diversificação de função (forma de intermediar } \\
\text { negócios entre clientes e fornecedores) }\end{array}$ & 80,0 \\
\hline & \multirow{2}{*}{ Ganho de escala } & Ampliação das transações & 80,0 \\
\hline & & Aquisição de outras trading companies & 60,0 \\
\hline \multirow{6}{*}{ 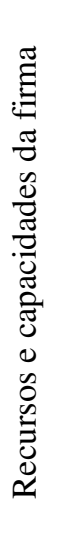 } & \multirow[b]{2}{*}{$\begin{array}{l}\text { Recursos e capacidades } \\
\text { físicas }\end{array}$} & Criação de Centros de Negócios & 100,0 \\
\hline & & Aquisição de equipamentos de comunicação & 80,0 \\
\hline & \multirow{4}{*}{$\begin{array}{c}\text { Recursos e capacidades } \\
\text { humanas e } \\
\text { organizacionais }\end{array}$} & Expansão e diversificação de fornecedores & 80,0 \\
\hline & & Expansão e diversificação de clientes & 80,0 \\
\hline & & $\begin{array}{l}\text { Intensificação da relação com clientes varejistas em } \\
\text { processo de internacionalização }\end{array}$ & 60,0 \\
\hline & & $\begin{array}{l}\text { Entrada em novos mercados via relacionamento com } \\
\text { clientes }\end{array}$ & 80,0 \\
\hline
\end{tabular}

REAd I Porto Alegre - Edição 74 - N 1 - jan/abr 2013 - p. 219-246 
Estratégia em negócios internacionais: evidência em uma trading company que atua entre economias emergentes

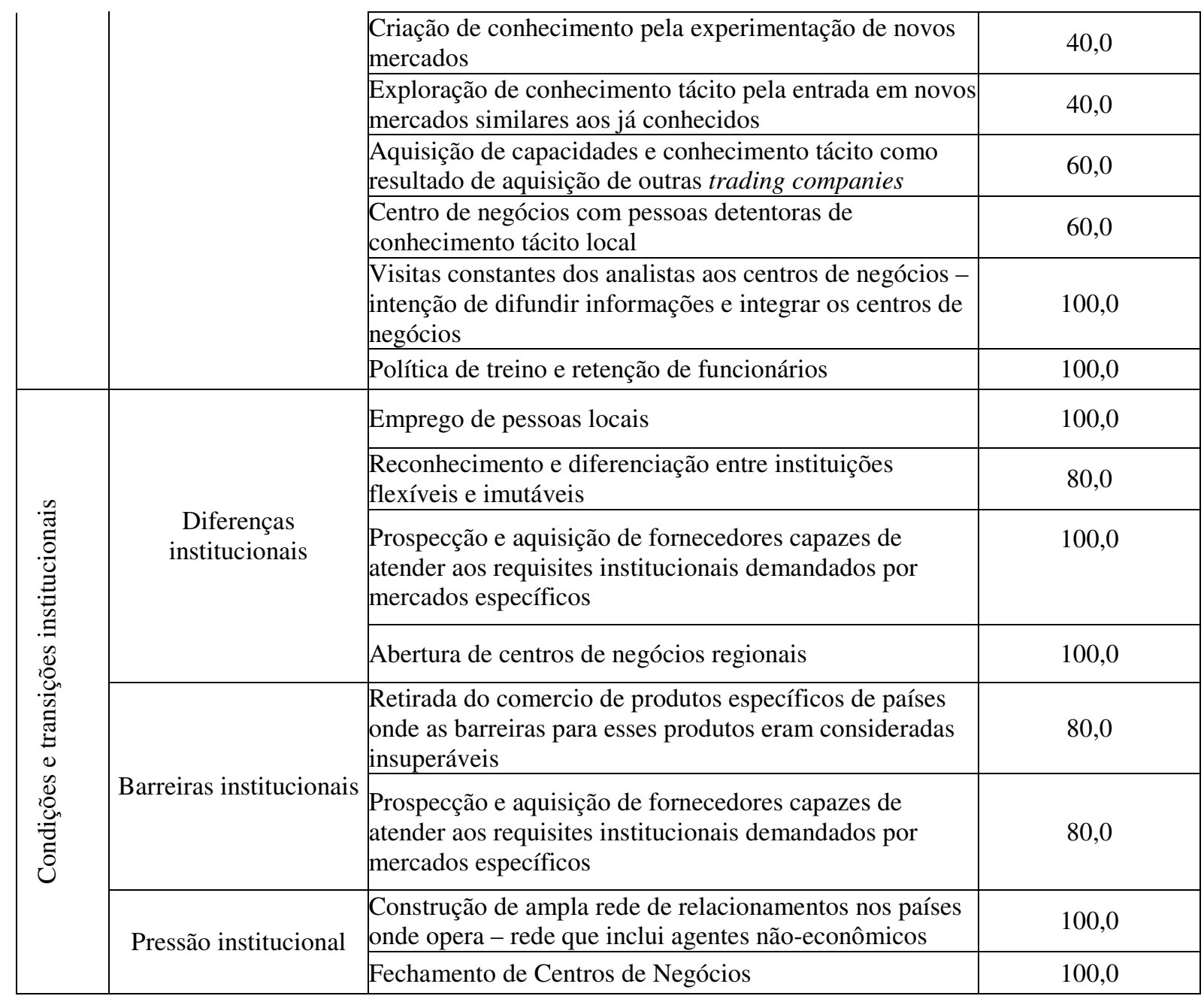

REAd I Porto Alegre - Edição 74 - N 1 - jan/abr 2013 - p. 219-246 